\title{
A construção da prática docente: reflexões sobre a relação entre a ação individual e o contexto social
}

\author{
The construction of teaching practice: \\ reflections on the relationship between \\ individual action and social context
}

Daniela ANJOS1

Debora DAINEZ ${ }^{2}$

Resumo

Abstract

O objetivo é refletir sobre o desenvolvimento da prática docente a partir da discussão de dois conceitos: gênero de atividade e habitus. Analisa-se fragmentos de um trabalho de intervenção realizado sob inspiração da metodologia em Clínica da Atividade, com professores do ensino fundamental de uma escola pública municipal do Estado de São Paulo. Com base nos resultados obtidos, entre eles o flagrar-se de uma professora em relaçáo aos modos de fazer e de se referir aos alunos, evidencia-se os embates entre o que se reitera na história de práticas da profissão docente e as (im)possibilidades de transformação da ação individual.

Palavras-chave: Habitus. Gênero de Atividade. Prática Docente.
Based on the discussion of two concepts, activity genre and habitus, this work reflects on how teaching practices develop. It analyzes parts of an intervention work following Clot's methodology that involved teachers of a primary public school in the State of São Paulo. Our results, in particular the astonishment of a teacher before her own praxis and ways to refer to pupils, evidence clashes between what repeats itself in the history of teaching practices and the possibilities to transform individual action.

Keywords: Habitus. Activity Genre. Teaching Practice.

1 Doutorado em Psicologia Educacional (FE-UNICAMP), Grupo de Pesquisa Pensamento e Linguagem (GPPL-Unicamp), Grupo Relações de Enisno e Trabalho Docente (USF). Professora do programa de pósgraduação Stricto Sensu da Universidade São Francisco. Av. Caetano Gornatti, 1101, casa 368, Jundiaí/SP. CEP: 13214-661. Cel (11)997203585.Email:<daniela.anjos.prof2015@gmail.com>.

2 Doutorado em Psicologia Educacional (FE-UNICAMP), Grupo de Pesquisa Pensamento e Linguagem, Professora (substituta) da Universidade Federal de São Carlos - campus Sorocaba. Rua Léa Strachman Duchovni, n.90, casa 17, Cond. Village Santa Candida. Bairro Parque Rural Fazenda Santa Cândida, Campinas/SP. CEP :13087-608. Cel (19)981387367. Email: <ddainez@yahoo.com.br>.

R. Educ. Públ.

Cuiabá

v. 27

n. 64

p. $91-108$ jan./abr. 2018 


\section{Introdução}

Este texto preocupa-se com a atividade de ensino e como é construída, levando em consideração a realidade da educação pública brasileira, as tensôes sociais que perpassam a trajetória da formação e a constituição da prática docente. Sabemos o quanto a atividade de ensino é complexa, estando relacionada com uma história de práticas que ultrapassam os sujeitos em situação imediata, e produzem efeitos no fazer pedagógico cotidiano.

Tendo isso em vista, propomos uma reflexão sobre a prática docente a partir de dois conceitos: gênero de atividade, formulado pelo pesquisador francês da Clínica da Atividade Yves Clot, e habitus, elaborado pelo também pesquisador francês Pierre Bourdieu. A opção em explorar esses conceitos, trabalhados a partir de áreas distintas do conhecimento, Psicologia e Sociologia, respectivamente, se justifica pela contribuição para pensarmos nos pressupostos da ação e/ou do dizer individual e em como eles se relacionam com o contexto social, possibilitando compreender a atividade laboral do professor a partir de uma perspectiva mais ampla.

A partir da discussão teórica dos referidos conceitos, tomamos como objeto de análise fragmentos de um trabalho realizado com professoras da educação básica de uma escola pública municipal do Estado de São Paulo, sob inspiração da metodologia em Clínica da Atividade. Trata-se de criar uma ambiência que, mediada pelo pesquisador, possibilite o confronto do sujeito diante de registros vídeogravados de situações de trabalho, oportunizando a verbalização e a compreensão sobre os dilemas de sua atividade profissional.

Assim, para a análise, procedemos de modo a tomar trechos referentes à situação de discussão de uma das professoras participantes da pesquisa com a pesquisadora diante das imagens registradas de seu trabalho com a turma. Nessa situação, a professora surpreende-se/espanta-se com a própria imagem, com o que se vê fazendo. Mediante a discussão analítica, propomos então uma reflexão sobre a construçâo da prática profissional, considerando os embates existentes entre o que se repete na história de práticas da profissão docente e as (im)possibilidades de transformação da ação.

\section{Gênero de atividade e habitus: conceitos em discussão}

Na busca por compreensão das práticas educativas no contexto escolar, e mais especificamente na tentativa de pensar a sua produção/reprodução, mobilizamos dois conceitos, que de campos de conhecimentos distintos, contribuem para pensarmos no entretecimento da ação individual com o contexto social: gênero de atividade (CLOT, 2010) e habitus (BOURDIEU, 1996). 
Tanto Clot quanto Bourdieu fazem a crítica do objetivismo e do subjetivismo, recusando a ideia de que a açáo individual seja diretamente determinada pela estrutura social, ou que seja independente dela. Ao se contraporem à visão dicotômica existente na relação entre a dimensão social e individual, os autores inscrevem a ação dos sujeitos em uma história de relaçóes e práticas.

Nesse sentido, Yves Clot, expressivo autor contemporâneo do campo da Psicologia do Trabalho, ancorando-se nos estudos da ergonomia francesa, da perspectiva histórico-cultural russa e da teoria enunciativa da linguagem, propóe uma abordagem teórico-metodológica nomeada Clínica da Atividade. Sua principal preocupação é compreender as dimensóes psicológicas envolvidas na relação do homem com o trabalho, bem como fornecer elementos para pensarmos em formas de ampliaçáo do poder de agir dos trabalhadores, com vistas à transformação das situaçôes de trabalho.

Para tanto, Clot (2006a, 2010) elabora o conceito de gênero de atividade a partir da discussáo com Ivar Oddone sobre a funçáo psicológica do coletivo de trabalho e da reflexão sobre o conceito de gêneros de discurso de Mikhail Bakhtin. Para o autor, além de modos de dizer que se estabilizam nos diferentes campos da atividade humana, haveria também os modos de fazer relativamente estabilizados. Parafraseando Bakhtin, Clot (2010, p. 121) afirma que "[...] se fosse necessário criar, a cada vez na ação, cada uma de nossas atividades, o trabalho seria impossível.” E continua explicando:

O gênero é, de algum modo, a parte subentendida da atividade, o que os trabalhadores de dado meio conhecem e observam, esperam e reconhecem, apreciam ou temem; o que lhes é comum, reunindo-os sob condiçóes reais de vida; o que sabem que devem fazer, graças a uma comunidade de avaliaçóes pressupostas, sem que seja necessário reespecificar a tarefa cada vez que ela se apresenta. É como uma senha conhecida somente por aqueles que pertencem a um mesmo horizonte social e profissional. (CLOT, 2010, p. 121-122).

Alguns autores têm mobilizado esse conceito para a análise do trabalho docente (FAÏTA, 2004; ROGER, 2007; SAUJAT, 2004). Saujat (2004) diz que a análise da atividade de professores iniciantes revela a existência dessas formas estáveis, maneiras de agir reconhecidas e validadas pelo meio profissional. Formas que são desconhecidas por aqueles que ingressam na profissão, o que acaba acentuando as dificuldades do início profissional.

Dessa forma, a noção de gênero de atividade nos ajuda a compreender os previsíveis e os pressupostos sociais, que muitas vezes permanecem como implícitos 
na orientação da ação em um determinado meio de trabalho. Nos gestos que marcam certo métier conserva-se e transmite-se a história social da atividade.

Essa discussão sobre a trama do gênero da atividade, constituída historicamente, que orienta a mobilização das práticas e discursos, nos remete, então, ao conceito de habitus, elaborado por Pierre Bourdieu na defesa de um modo de conhecimento praxeológico em oposição às perspectivas fenomenológica e objetivista. Tal conhecimento tem por objeto as relaçóes dialéticas entre as estruturas objetivas e as disposiçóes estruturadas nas quais elas se atualizam e que tendem a se reproduzir (BOURDIEU, 1983).

As estruturas constitutivas de um tipo particular de meio (as condições materiais de existência características de uma condição de classe), que podem ser apreendidas empiricamente sob a forma de regularidades associadas a um meio socialmente estruturado, produzem habitus, sistemas de disposiçôes duráveis, estruturas estruturadas predispostas a funcionar como estruturas estruturantes, isto é, como princípio gerador e estruturador das práticas e das representaçôes que podem ser objetivamente reguladas e regulares sem ser o produto da obediência a regras, objetivamente adaptadas a seu fim sem supor a intenção consciente dos fins e o domínio expresso das operaçôes necessárias para atingi-los e coletivamente orquestradas, sem ser o produto da ação organizadora de um regente. (BOURDIEU, 1983, p. 60-61).

O habitus ajuda a explicar porque determinadas ações são realizadas em detrimento de outras. Define "[...] modos adequados de agir... socialmente aceitos, que fazem sentido para o indivíduo e para o seu grupo de uma forma tal que são percebidos como naturais, inquestionáveis" (LUGLI, 2007, p. 28). Nas palavras de Bourdieu, "O habitus é a mediação universalizante que faz com que as práticas sem razão explícita e sem intenção significante de um agente singular sejam, no entanto, sensatas, razoáveis e objetivamente orquestradas [...]" (BOURDIEU, 1983, p. 73).

De acordo com o autor, a história existe em seu "[...] estado objetivado, quer dizer, a história que se acumulou ao longo do tempo nas coisas, máquinas, edifícios, monumentos, livros, teorias, costumes, direito, etc., e a história em seu estado incorporado, que se tornou habitus" (BOURDIEU, 2010, p. 82).

Esse conceito também tem sido salientado na análise do trabalho docente. Considera-se que há um habitus professoral que se manifesta nos momentos 
em que surgem situações imprevistas, nas quais é necessário agir rapidamente (LUGLI, 2007; SILVA, 2005). Lugli (2007) comenta que “[...] as raízes dessas açôes, que parecem instintivas, podem ser localizadas no repertório de práticas que todo docente acumula desde suas vivências como aluno.”

Nessa perspectiva, para se inserir na profissão, faz-se necessário aprender o habitus professoral, ou seja, se apropriar das maneiras de fazer as coisas próprias da profissáo e da instituição em que se trabalha.

Como é possível notar, as abordagens de Bourdieu (1983, 1996, 2010) e Clot $(2006 a, 2010)$ se encontram quando apontam para uma relação íntima entre a história da pessoa e a história da instituiçấo, entre os processos individuais e a dinâmica social.

Clot (2006a), ao analisar o gesto de cumprimentar em uma situação vivenciada e descrita por Jerome Bruner numa aldeia nos Alpes, afirma:

Quando nos tornamos parte de uma comunidade social, não só somos introduzidos num conjunto de convençôes de práxis, como também essa partilha nos inclui num mundo de práticas que transcendem o indivíduo. De fato, o gênero pode definir-se como o conjunto das atividades mobilizadas por uma situação, convocadas por ela. Ele é uma sedimentação e um prolongamento das atividades conjuntas anteriores e constitui um precedente para a atividade em curso: aquilo que foi feito outrora pelas geraçôes de um meio dado, as maneiras pelas quais as escolhas foram decididas até entâo nesse meio, as verificaçóes às quais ele procedeu, os costumes que esse conjunto enfeixa. (CLOT, 2006a, p. 44).

Bourdieu (2010), igualmente, escreve sobre a questão do uso do mesmo gesto:

Aquele que tira o chapéu para cumprimentar reativa, sem saber, um sinal convencional herdado da Idade Média no qual, como relembra Panofsky os homens de armas costumavam tirar o seu elmo para manifestarem as suas intençôes pacíficas. Essa atualização é consequência do habitus, produto de uma aquisição histórica que permite a apropriaçáo do adquirido histórico. A história no sentido de res gestae constitui a história feita corpo e que não só actua como traz de volta aquilo que a leva [...] (BOURDIEU, 2010, p. 82). 
As duas situaçóes realçam a questão da incorporação dos modos de fazer, que pode estar implicada num gesto rotineiro que escapa a quem não faz parte do grupo social. Os gestos têm uma história, não são frutos da criação pura e simples do sujeito que os realiza.

Podemos dizer, assim, que a ideia de habitus e de gênero de atividade remete aos modos de ação que, estabilizados e inscritos num conjunto de práticas, são incorporados nos sujeitos e apresentam aspectos implícitos, não conscientes.

Clot (2006a) nos fala do gênero como a parte subentendida da atividade, um interposto social que se manifesta como uma comunidade de avaliaçóes comuns pressupostas que regulam a atividade individual de maneira tácita, garantindo que os sujeitos saibam o que devem fazer em determinada esfera social. Bourdieu (1996) enfatiza o sentido do jogo de relaçóes e práticas, que faz com que se faça algo no momento próprio, sem ter havido necessariamente o planejamento da ação e a tematizaçáo da regra que permite gerar uma conduta adequada.

Se é possível ver aproximaçóes entre os dois conceitos, há também diferenças fundamentais. Dentre elas encontra-se, sobretudo, a concepção de atividade. Para Clot (2009), a realização da atividade pelo sujeito carrega em si o estilo pessoal que condensa a possibilidade da criaçáo do novo. Dito de outro modo, o conceito de gênero de atividade traz uma visão dinâmica da atividade do sujeito que está sempre relacionada ao gênero, mas também carrega vias de ação que permitem questionar o gênero. A atividade não é somente produto do gênero, mas também uma realização única do sujeito.

Isso também permite a ação, através das operaçôes que a levam a termo, para tornar visível o que pode ser realizável e aquilo que alguém nem mesmo suspeitava. O Objeto da ação tem vida própria. Porém é uma vida dupla. A ação, ao realizar-se a si mesma, reduz a atividade, mas simultaneamente abre-se a novas possibilidades. (CLOT, 2009, p. 293).

Retomando a contribuição de Leontiev, Clot (2006b) afirma que na busca de um objetivo, uma ação pode se deparar com resultados inesperados, que se tornam fonte de novas mobilizaçóes psíquicas, reconfigurando o objetivo inicial. "A atividade é, portanto, construtora de novos motivos que o sujeito descobre depois da experiência... nascidos não a partir dele mesmo, mas do real de sua atividade que, em parte, lhe escapa" (CLOT, 2006b, p. 233).

Para ele, diferentemente de Bourdieu, os inesperados do real não fariam apenas o sujeito buscar nos esquemas incorporados as respostas para a ação (habitus), mas podem provocar novas realizaçóes. Outro aspecto a ser ressaltado, ainda, é a visão 
de coletivo de trabalho, vinculada ao conceito de gênero de atividade, que coloca ênfase na necessidade de os coletivos profissionais debaterem, eles próprios, sobre os critérios de qualidade e eficiência do trabalho. A vitalidade do gênero depende, justamente, desse debate, das variações estilísticas em interlocução.

Dessa maneira, se Clot contribui para pensarmos na ampliação das potencialidades de transformação da prática no coletivo, incitando um processo de constante criaçáo e protagonismo, Bourdieu nos ajuda a refletir sobre a força das condiçóes materiais de existência, que muitas vezes dificulta, senáo impede, a produção de novos possíveis.

É compreendendo essa tensão e complexidade que permeia a dinâmica das práticas docentes, a institucionalizaçáo delas e o ingresso dos professores no meio profissional que nos detemos à análise do material empírico produzido com as professoras.

\section{Metodologia}

De forma mais detalhada, consideramos necessário explicar a proposta metodológica da Clínica da Atividade. O pressuposto desse método é a descoberta de novas formas possíveis da ação, baseando-se na ideia de que a atividade realizada não é senão uma dentre muitas outras possibilidades de realização. De acordo com Clot (2005), fazendo referência a Vigotski, o homem é pleno a cada minuto de possibilidades não realizadas, e essas possibilidades, por não serem realizadas, não são menos reais.

Por um lado, descobre-se que a açáo realizada e observável náo tem o monopólio do real da atividade. [...]. O nãorealizado, possível ou impossível, é parte dele. O que se faz - e que podemos considerar como a ação realizada nada mais é que a atualização de uma das ações realizáveis na situação em que surge. [...]. Como vemos, o real da atividade também é o que não se faz, o que não se faz mais, mas também o que se busca fazer sem conseguir - o drama dos fracassos - o que quereríamos ou poderíamos ter feito, o que pensamos poder fazer ainda, nem que seja em outro lugar; o que não pensávamos poder fazer o prazer da descoberta - ou ainda o que fizemos sem querer. Ainda é preciso acrescentar - paradoxo frequente - o que se faz para náo fazer o que temos de fazer [...] (CLOT, 2005, p. 5-6, tradução nossa). 
Essas atividades impedidas, suspensas, contrariadas, continuam agindo nos sujeitos e devem ser consideradas na análise do trabalho. No entanto, não se referem a algo que se pode observar diretamente; é por isso que foram criados os métodos indiretos de análise do trabalho. O objetivo é permitir aos sujeitos a transformação da experiência vivida em objeto de uma nova experiência, ou seja, ir ao encontro de outras realizaçóes possíveis, desenvolver novos objetos e destinatários, o que possibilita o desenvolvimento da atividade.

A partir dessa metodologia busca-se compreender como se organiza a transformação da ação, ao mesmo tempo em que se propóe um meio de transformação da ação. "O desenvolvimento é, portanto, ao mesmo tempo seu objeto e seu método privilegiado" (CLOT, 2005, p. 7, traduçáo nossa). Trata-se de construir um quadro metodológico que visa provocar o desenvolvimento a fim de estudá-lo. A transformação não é consequência da compreensão, a transformação é a condição da compreensão. Apoiando-se na proposição de Vigotski de que um corpo só mostra o que é em movimento, a Clínica da Atividade defende que para conhecer a atividade de trabalho é preciso colocá-la em movimento (ROGER, 2007).

A primeira etapa deste trabalho começa com observaçóes e videogravaçóes da atividade de trabalho. $\mathrm{Na}$ autoconfrontaçáo simples, o trabalhador assiste as cenas videogravadas de seu trabalho com um pesquisador. $\mathrm{O}$ sujeito torna-se um observador externo de sua própria atividade, "[...] em posição exotópica a respeito de seu trabalho e face a escolhas ou dilemas que ele redescobre na sua atividade, o que era operação incorporada e resposta automática torna-se questão" (CLOT, 2010, p. 226).

No diálogo que ele deve assumir com o pesquisador e para sustentar essa troca sobre os enigmas de sua atividade, geralmente o sujeito busca náo ficar só. Para sustentar aquilo que é difícil dizer na autoconfrontação simples, muitas vezes o trabalhador convoca o coletivo, não fala só em primeira pessoa, usando $e u$, mas traz um nós em seu enunciado - a gente faz assim. O sujeito é visto não somente com seus próprios olhos - observação interior - mas com os olhos de um observador exterior que não é mais somente o pesquisador, mas o métier, ou ainda o coletivo. Dizendo de outro modo, na busca por justificar um dado modo de realizar a atividade, o sujeito dispóe da história coletiva do métier, que pode lhe fornecer elementos para explicar o que se vê fazendo na tela.

Em um certo sentido, a Clínica da Atividade atinge aqui seu primeiro objetivo. Graças à autoconfrontação simples podemos recolher resultados sobre o que um coletivo faz ou não faz da tarefa prescrita; podemos acessar sua função de recurso psicológico na atividade pessoal (CLOT, 2010).

No entanto, essa possibilidade de dispor da história do métier para justificar suas açóes pode fechar o diálogo, impedir a atividade interior. A autoconfrontação cruzada 
vem justamente no sentido de trabalhar essa história coletiva, sendo considerada uma pesquisa da controvérsia. Um de seus objetivos é dar visibilidade aos diferentes pontos de vista e concepçóes sobre os modos de realizar uma mesma atividade.

Dois trabalhadores irão juntos observar uma mesma videogravaçáo de um colega. Ao comparar suas maneiras de fazer ou de dizer na situação observada, eles rapidamente encontram diferenças. $\mathrm{O}$ a gente faz assim torna-se objeto de controvérsia no diálogo com outro trabalhador, que frequentemente diz não é bem assim, faço de outro jeito.

$\mathrm{Na}$ autoconfrontação cruzada há uma mudança de destinatário. Agora não se fala mais só ao pesquisador, mas ao colega de trabalho. Essa mudança de destinatário modifica a análise. A autoconfrontação cruzada tem por objetivo organizar a controvérsia e com isso possibilitar o desenvolvimento do métier.

Desse modo, "[...] o coletivo de trabalho pode se sentir um pouco menos prisioneiro das verdades do momento [...]", podendo ser colocado em questão. Os trabalhadores juntos podem encontrar novos modos de agir; "[...] o objetivo é reencontrar, a partir de imagens do que foi feito e daquilo que os profissionais disseram daquilo que fizeram, aquilo que poderá ser feito" (CLOT et. al., 2001, p. 6, tradução nossa).

No contexto de uma pesquisa de doutorado, convidamos quatro professoras dos anos iniciais do ensino fundamental para participar de um grupo de estudos sobre a prática docente, sob inspiração da metodologia em Clínica da Atividade (CLOT, 2010), mais especificamente, as autoconfrontaçôes (simples e cruzadas).

O trabalho com as professoras foi realizado entre setembro de 2008 a setembro de 2010. Elas possuem em média dez anos de experiência, são formadas em Pedagogia pela mesma universidade e ensinam no primeiro ciclo dos anos iniciais do ensino fundamental.

Nesses dois anos de trabalho, a pesquisadora fez videogravaçóes das aulas das quatro professoras, em dias previamente combinados. Foram agendados encontros para que elas assistissem aos vídeos na presença da pesquisadora (autoconfrontação simples), e em outro momento na presença de outra colega de trabalho (autoconfrontação cruzada). Além desses momentos houve reunióes com a participação das quatro professoras com o objetivo de decidir que cenas recortar para assistir nas sessóes de autoconfrontaçóes, compartilhar as análises que vinham sendo feitas e discutir sobre os temas que emergiam das análises realizadas. Dentre os temas discutidos nessas reunióes podemos destacar: organização do trabalho pedagógico; condiçôes de realização do trabalho do professor; avaliações externas; relaçáo com os outros professores, gestão e pais; indisciplina e violência; dificuldades de aprendizagem; heterogeneidade de saberes entre as crianças; papel/postura do professor. 
Para fins desse trabalho, elegemos um recorte de uma situação de autoconfrontação simples que envolve uma das professoras e a pesquisadora.

\section{Sobre as (im)possibilidades de transformação da ação}

Nesta seção, como já fora mencionado, destacamos para análise trechos de uma das autoconfrontações simples realizadas com uma das professoras (Irene ${ }^{3}$ ).

Irene tinha o sonho de ser médica, mas fez formação para ser professora por influência de seus pais. Ela fez magistério (1995-1998) e Pedagogia (1999-2002). Trabalha na rede municipal de Campinas desde o ano de 2000. No período da pesquisa ela trabalhava em uma escola situada em uma regiáo periférica da cidade. Um bairro com poucos equipamentos públicos, estrutura precária, com uma história de violência e tráfico de drogas. $\mathrm{O}$ fragmento apresentado neste texto é referente a uma turma de segundo ano do ensino fundamental, composta por 28 alunos.

Durante a autoconfrontação, assistimos a um vídeo que mostrava uma cena em que a professora está dividindo os alunos em grupos para um trabalho que seria realizado logo após. Trata-se da produção de um jornal, e cada grupo seria responsável por uma parte. Ela faz um sorteio para saber quem seria o líder de cada grupo. Ao fazer o sorteio brinca com os alunos, para que eles adivinhem o nome que foi sorteado. Ela vai dando dicas para que eles descubram de quem se trata, e nessas dicas ela fala das características de alguns alunos:

I: Próximo lider de objetivo, de Esportes. É um menino ou uma menina?

Vários: Meninooo! Meninaaa!

I: É uma menina.

Meninos: Ahbhh.

I: Ela já teve cotada pra ser líder lá [da sessão de] entrevista.

Criança1: Heloisa4.

Criança2: Nâo, Talita.

A Leticia.

A Loren.

Nicole.

Gisele.

I: Gisele. Não é Nicole, é Gisele. É Gisele T. ou Gisele F??

3 Nome fictício

4 Nomes fictícios 
Crianças: T!

I: É uma pessoa que pra arrancar um sorriso é difícil; quem que é mais difícil pra arrancar um sorriso?

Criança: A Gisele.

I: Gisele F. ou Gisele P.?

Crianças: Gisele F.

I: Quem que acorda com um mau humor (piii) pra vir pra escola?

Gisele F., Gisele P.?

I: Não é a Gisele F., é a Gisele F. vem feliz pra escola.

Crianças: Ah, Gisele P.

I: Quem é mal-humorada?

Vários: Gisele P.!

I: A Gisele P. que vai ser lider do objetivo de dicas culturais. Agora que sirva pra senhora vir mais humorada pra escola, hem Gi.

Criança: Mal-humorada [risos].

I: Próximo lider de objetivo. Vai ter que rebolar. Vai ter que balançar pra trabalhar. É um menino.

Vários: Eehhh!!!!!

I: Porque que eu falei que é um menino que vai ter que rebolar, rebolar, trabalhar, trabalhar. Crianças: É o Leonardo.

Leonardo: Que Leonardo?

Criança: Você trabalha bastante.

I: Não, se fosse o Leonardo tava bom, porque o Leonardo trabalha, ele vai arrancar a orelha de todo mundo do grupo dele que não trabalhar. Agora é o contrário. É um menino que não rebola, não trabalha, dá trabalho.

Crianças: Vitor. Vitor! Vitor Rodrigues.

I: Vitor Rodrigues.

Na cena videogravada, a professora mostra-se muito à vontade. Está cantando, dançando, brincando com as crianças. E é o que ela destaca num primeiro momento da análise em autoconfrontação:

Achei legal. Eu gosto quando eu me vejo assim, alegre... Eu gosto dessas cenas que eu sou mais despojada, eu gosto dessas aulas em que eu sou mais, mais solta, mais criativa [...]. Eu prefiro acho que essa Irene muito mais solta, muito mais espontânea, eu acho muito mais divertido, eu acho que isso marca muito mais o aluno e eu acho que é muito mais gostoso...

Mas, num segundo momento de análise, há uma mudança de perspectiva, um desconforto com a própria imagem.

D: Acho que tem uma outra coisa que aparece nesses trechos, que nessa escolba dos lideres fica evidente algumas marcas dos alunos no grupo: o que dá trabalho, a aluna mal-humorada [...]. Queria que você falasse um pouquinho disso. 
I: Que eu até fui falando ali durante o vídeo, que eu acho que eles não vão para o psicólogo futuramente, 'ai, minha professora me chamava de mal-humorada', pelo modo que eu coloco. Não sei, eu espero que daqui a vinte anos eles não precisem ir para o psicólogo por causa da marca da professora, que falava que mal, eu imagino que não, que nem quando eu falei lá a Gisele ficou sorrindo, 'sou eu a mal-humorada, sou eu'... [risos]. Mas, eu imagino que não. Sáo características assim que você vai construindo com eles, você vai percebendo e que, assim, eu imagino que eu enquanto professora, o modo que eu ajo com eles, que eu pontuo para eles, eu não sei se é naturalidade, o modo como eu coloco seja tão natural - não sei se natural é a palavra certa - que eles vão percebendo com um modo natural, isso vai sendo naturalizado por eles, né, eu não vou rotulando eles, porque eu acho que assim. Eu sofri muito preconceito de várias professoras, até mesmo na faculdade... Mas... e assim no magistério também tive vários problemas, tal, mas eu imagino, na minha consciência, minha né, que eu estou fazendo de um modo diferente. Quando eu rotulo esses alunos, eu imagino que eu faço de um modo diferente. A minha prática com eles, eu náo vejo, eu quero acreditar, vamos colocar assim, eu quero acreditar que eu estou fazendo de um modo diferente porque lá eu estou colocando de um modo brincando [...]. Ai, não! Para que você tá fazendo eu repensar? [risos].

[...]

I: Ai, não, para que você tá fazendo eu repensar? [risos].

D: Eu não falei nada.

A: É o escutar-se.

I: [em tom de brincadeira] Não quero mais ver esses vídeos, Dani...

I: Não porque eu estou vendo ali, eu vejo uma Irene brincando, sorrindo. Ai, Dani, eu acho que eles não vão ter problemas não, eu quero acreditar que eles não vão ter problema. Só isso, Dani, passa para o próximo, senão eu que vou para o psicólogo a hora que eu sair daqui... As outras coisas, Dani, não que eu estou traumatizando as coitadinhas das crianças...

D: Eu não disse isso.

I: Não, Dani, mas ó, chamando a criança de bagunceira [risos], a outra de mal-humorada o tempo inteiro, ainda mais que eu fico falando o tempo inteiro que ela... mal-humorada, não sei que... E ai eu vejo que as crianças reconhecem essas crianças, Dani. Isso que é o pior, Dani. I: Deu medo agora.

D: Por quê?

I: Porque vai que eu estou traumatizando com eles.

A: Eu acho que essa questão de traumatizar, você está agora suspeitando que é possivel?

I: Eu de um lado quero acreditar que náo, do que eu acredito, do modo que eu sou, do que eu faço, de como eu ajo com eles, não. De todos os valores que eu trago, de todo ser que eu sou, digo não, mas ao ver e saber que eles, eles enxergaram ser isso que eu apontei pra eles, e que eles são seres que vêm de outras coisas em casa também, com outros valores, com outras crenças, entendeu? Eles não são a Irene, ninguém garante o que eles vão pensar...

A partir da pergunta da pesquisadora (1-3) Irene é levada a pensar no sentido de seus dizeres. De uma admiração pelo seu modo de agir, vai-se percebendo rotulando os alunos. Prática que ela dizia/acreditava não fazer. A imagem que tinha 
de si náo coincide com a imagem vista na tela. Vemos um intenso movimento de seu pensamento aqui. Há um diálogo dela com a imagem de si projetada no vídeo. Ela usa o termo imagino e acredito, quero acreditar algumas vezes, na tentativa de analisar os sentidos/efeitos da atividade realizada:

... eu imagino... que são características que você vai construindo com eles...

... eu imagino que o modo como eu coloco seja táo natural...

... eu imagino que estou fazendo de um modo diferente, quando eu rotulo esses alunos...

... eu quero acreditar que eu estou fazendo de um modo diferente

Dá indícios de incerteza, incertezas produzidas com o confronto da imagem no vídeo. Parece haver uma contradição ou um descompasso entre o que se diz sobre o que se deve fazer, trabalhar não rotulando, e o que realmente se faz quando eu rotulo esses alunos.

Confrontada pela questão da pesquisadora, ela fica buscando responder, busca uma justificativa para o que fez. Ao tentar responder ela vai se flagrando também com o que diz, como, por exemplo, entre as linhas 11 e 13 ela usa a palavra naturalidade como resposta, mas logo depois a questiona.

O sentido do rotular, empregado nessa análise, que ela faz não estava ligado explicitamente à questão do saber/não saber dos alunos, mas dizia respeito ao comportamento e características pessoais, coincidindo com o sentido de atribuir qualidade. No entanto, Irene faz essa associação ao lembrar que ela própria, quando aluna, sofreu preconceito por parte de professores e esse preconceito ao qual ela se refere estava ligado à questão do saber. Num texto em que escreveu sobre sua constituição como professora ela explicita isso:

Quando estava cursando o magistério, em um Centro Municipal de formação técnica além das disciplinas também aprendi com as atitudes das minhas professoras. Aprendi o que não fazer com os meus alunos: dizer que eles não sabem, não são capazes, ou que eles nunca serão bons os suficientes no que fazem.

E... isso foi o que uma professora contribuiu com a minha formação, ao dizer na frente das minhas colegas que eu não era boa, que meus trabalhos nunca estavam bons como os das minhas colegas, e que eu jamais seria uma boa professora. Será que sou?

Como uma prática que ela rejeita, inclusive porque experienciou na pele, e não quer repetir com seus alunos, acaba sendo reproduzida?

Ela não quer fazer, ela tenta não fazer, mas mesmo assim acaba "rotulando" os alunos... Ela tenta convencer a si mesma que faz de um modo diferente, que não é como os professores do magistério fizeram com ela. Mas não consegue ter certeza se realmente faz diferente. Parece difícil dizer/explicar o que ela está fazendo. 
Como se ela própria não tivesse clareza. $\mathrm{O}$ movimento de reflexão é tão intenso que ela pede para pararmos de falar sobre isso e passemos à outra cena.

Irene se espanta aqui, não só com os seus enunciados em aula, mas pela forma como eles produzem sentido para as crianças: eu vejo que as crianças reconhecem essas crianças... Isso que é o pior. A fala da professora sobre seus dizeres em sala de aula evidencia o flagrar-se com relaçáo a seus modos de se referir aos alunos; modos que apontam para marcas que se tornam reconhecíveis por todos; dizeres que produzem sentidos que se cristalizam.

Pensando na singularidade da enunciaçáo produzida por Irene, um ponto que merece destaque é o modo como ela diz: a brincadeira, o jogo com as palavras, misturando com cançóes conhecidas, a entonação, os gestos... O dizer aqui é acompanhado por um jogo de cena característico dessa professora. Um estilo pessoal, ao qual ela própria faz referência no início da análise.

Como poderíamos pensar na constituição desse estilo/ marca profissional de Irene? De que modo ela se relaciona com o gênero em funcionamento - de discurso, de atividade?

Concordamos com Clot (2010, p. 126) na definição de estilo individual, como sendo "[...] a transformação dos gêneros na história real das atividades no momento de agir em função das circunstâncias [...]". Trata-se de uma síntese, um desenvolvimento da história coletiva, e não uma criação solitária do sujeito. "O gênero profissional é constitutivo do estilo, o que exclui que possamos fazer desse último um simples atributo psicológico privado" (CLOT, 2010, p.110).

No entanto, Clot vai afirmar que o estilo tem uma dupla vida. Ele não se acha apenas relacionado com o gênero, mas também com a história pessoal do sujeito.

O estilo é igualmente, a distância que um profissional interpóe ente sua açáo e a sua própria história, quando ele a adapta e retoca, colocando-se à margem dela por um movimento, uma oscilação, aí, às vezes, também rítmica consistindo em se afastar dela, em solidarizar-se e confundirse com ela, assim como em desembaraçar-se dela, de acordo com as contínuas modificaçôes de perspectivas que podem ser consideradas, igualmente, como criaçôes estilísticas. (CLOT, 2006a, p.128).

Tal elaboração é sustentada na contribuição de Vigotski para pensar a relação entre a história pessoal e social: "[...] a atividade conjunta do sujeito com os outros é a mola propulsora de sua história” (CLOT, 2006a, p. 128).

Nessa situação específica, é curioso que a mesma cena provoque admiração e espanto. Irene ressalta o modo como age com os alunos, gosta de se ver 
brincando com eles, mas ao mesmo tempo faz a autocrítica quando à questão dos rótulos. Admira o modo como diz e age e náo o conteúdo do que diz, o que aponta para a complexidade da constituição profissional, dos modos de dizer, de fazer em sala de aula.

Ela ressalta a marca da professora que marca os alunos, que os fazem lembrar dela com carinho mesmo depois que deixa de ser professora deles. Mas há também aqui o risco do gesto, da marca como rótulo, que pode discriminar, constranger os alunos.

Ao retomar o conceito de gênero de atividade, vemos que, para além de um estoque de práticas que se apresenta, de modos de dizer e fazer partilhados, parece haver a reprodução de uma lógica de funcionamento que escapa às intençóes dos sujeitos, algo que se encontra inscrito numa história de práticas, que estaria incorporado. Aqui, o conceito de habitus pode contribuir para a compreensão daquilo que se reproduz independente da vontade do sujeito: o fato de a professora se perceber rotulando os alunos, agindo mesmo contra aquilo que acredita, aponta para o funcionamento do habitus, de uma reproduçáo de práticas ligadas à sua própria história de escolarização, ainda que de modo inconsciente. Alguns autores apontam que em muitos casos os anos passados nos bancos escolares acabam sendo mais fortes do que a formaçáo profissional, e por isso propóem a narrativa autobiográfica como processo de formação, tendo como objetivo, dentre outros, a desnaturalização de certas práticas (CATANI, et al., 1997).

Irene teve a oportunidade de vivenciar esse processo de desnaturalização a partir da análise em autoconfrontação. Primeiro, ela admira o que vê, depois se espanta, busca palavras para se justificar, e acaba por admitir que rotula. Esse processo pode ser ocasiáo para que ela transforme sua prática, que provoque desenvolvimento.

Aqui, podemos estabelecer uma relação entre os trabalhos de Bourdieu e Clot: a defesa por um desvelamento dessas açóes incorporadas para que uma transformação seja possível. No entanto, isso se faz por vias diferentes. Para Bourdieu, o caminho é a análise sociológica (CATANI, 2007); para Clot, o engajamento dos profissionais numa análise da atividade por eles próprios, proposta pela metodologia em Clínica da Atividade (CLOT, 2005). Para nós, no diálogo com esses autores, pensamos que a possibilidade de transformação pode residir na análise das relaçóes entre a ação individual e o contexto social, realçando as contradiçóes e os dilemas que circunscrevem a prática de ensinar. Irene reproduz em seus modos singulares de agir e de dizer o processo de rotulaçáo que se estabelece historicamente como prática social, como prática escolar. E, na relaçáo com o outro-pesquisador, ao se dar conta disso, tem a perspectiva de novas possibilidades de orientação da atividade de ensino. 
Enfim, nesse episódio, vemos indícios da complexidade do gesto de ensinar. Ainda que o desejo da professora seja o de não marcar, não rotular, as açóes realizadas entram em um jogo de relaçóes que produzem efeitos e sentidos contraditórios, o que resulta, por exemplo, na reprodução de algo que não condiz com os princípios teóricos, ainda que sejam fortemente proclamados e estejam claramente assumidos. Podemos considerar que esses efeitos e sentidos se produzem no jogo de relaçóes e posiçóes sociais mais amplo, trazendo implicados o horizonte social, imagens e palavras que impregnam o imaginário social, as demandas escolares, as histórias das famílias, das professoras e de cada criança, do grupo que se forma numa sala de aula, etc.

\section{Considerações Finais}

Ao considerarmos a história de práticas elaboradas, estabilizadas no campo profissional, foi possível articularmos os conceitos de habitus e gênero e tecermos discussóes sobre aquilo que (não) muda no processo de constituição da prática docente.

Apesar de assumirmos com Clot o conceito de atividade, que não é apenas um produto do gênero, mas está a ele relacionado, consideramos que dado o campo de atividade analisado - o campo da educação, da educação pública brasileira o conceito de habitus traz uma contribuição importante ao ressaltar o peso das condiçóes objetivas de vida naquilo que é realizado. O conceito de habitus ajuda a compreender a reprodução das práticas que se inscrevem nas açóes cotidianas e são incansavelmente repetidas sem que se tenha consciência delas.

Ainda, quando Clot comenta sobre o processo de estilização como sendo dependente da apropriaçáo do gênero, conjecturamos que tal processo de apropriação já afeta os modos de fazer e pensar dos professores. Desse modo, o processo social impacta inescapavelmente o processo de (re)produção da ação individual nas várias esferas de atividade.

Sobre a metodologia em Clínica da Atividade, ressaltamos ser essa uma via profícua por viabilizar formas de elaboração da consciência - individual e coletiva, com vistas à transformação das condições e formas de realização do trabalho. A professora teve a oportunidade de dialogar coletivamente sobre os dilemas e as facetas de sua atividade, confrontar-se consigo mesma e com o outro, num flagrar-se nas práticas que acreditava não fazer na percepção de conflitos do métier, gerando a possibilidade de desenvolvimento. Vimos que, de fato, as situaçôes vivenciadas propiciaram e provocaram transformações.

Poderíamos pensar na fecundidade desse tipo de procedimento para discorrer sobre o trabalho docente e, em especial, a formação inicial e 
continuada. Valeria um investimento em conhecer o que de fato se faz na realidade concreta da escola, e coletivamente discutir os modos de fazer, debatendo sobre as diferentes soluções encontradas/não encontradas, as diferentes concepções e preocupações... Argumentamos que o coletivo afeta a atividade de ensinar. Fortalecer o coletivo de trabalho na instituição pública é, portanto, fundamental para a organização da ação do sujeito, sendo que com a organização da ação do sujeito tem-se a possibilidade de organização da ação da atividade de ensino.

Contudo, resta-nos ainda pensar na questão de como fazer tal discussão chegar a promover mudanças substanciais. Pois, mesmo que se discuta coletivamente os modos de fazer e se busquem soluçóes mais apropriadas para lidar com os dilemas enfrentados, há questóes estruturais sobre o modo como a escola está aparelhada, que ultrapassam as formas de ação, ainda que de um coletivo de trabalho organizado. Seria necessário transformar o sistema, repensar a configuração escolar.

\section{Referências}

BOURDIEU, P. Esboço de uma teoria da prática: precedido de três estudos de etnologia cabila. São Paulo: Ática, 1983.

BOURDiEU, P. Razóes Práticas. Sobre a teoria da ação. Campinas: Papirus, 1996.

BOURDIEU, P. O poder simbólico. Rio de Janeiro: Bertrand Brasil; 2010.

CATANI, D. B. et al. Docência, memória e gênero. Estudos sobre formação. São Paulo: Escrituras Editoras, 1997.

CATANI, D. B. A educação como ela é. Educação, São Paulo, v. 5, p. 1625, 2007.

Clot Y. L'auto-confrontation croisée en analyse dutravail: l'apport de la théori bakhtinienne du dialo-gue. In: FILLIETTAZ, L.; BRONCKART, J. P. (Org.). L'analyse des actions et des discours en situation detravail. Paris: De Boeck, sous presse, 2005.

CLOT, Y. A função psicológica do trabalho. Petrópolis: Vozes, 2006a.

CLOT, Y. Psicologia. In: BRAITH, Beth (Org.). Bakhtin: conceitos-chave. São Paulo: Contexto, 2006b. 
CLOT, Y. Clinic of activity: the dialogue as instrument. In: SANNINO, A., DANIELS, H., GUTIERREZ, K. (Ed.). Learning and Expanding with Activity Theory. London: Cambridge University Press, 2009.

CLOT, Y. Trabalho e poder de agir. Belo Horizonte: FabreFactum, 2010.

CLOT, Y. et al.; Les entretiens en autoconfrontation croisée : une méthode en clinique de l'activité. Education Permanent, Paris, 146, p. 17-27, 2001.

FAÏTA, D. Gêneros do discurso, gêneros de atividade, análise da atividade do professor. In: MACHADO, A. R. O ensino como trabalho: uma abordagem discursiva. Londrina: Eduel, 2004.

LUGLI, R. S. G. A construção social do indivíduo. Educaçáo, São Paulo, v. 5, p. 26-35, 2007.

ROGER, J. L. Essais de clinique l'activité. Toulouse: Erés, 2007.

SAUJAT, F. Spécificités de l'activité d'enseignants débutants et genres de l'activité professorale. Polifonia, Revista do programa de pós-graduação em estudos de linguagem, Cuiabá, UFMT, ano 7, n. 8, 2004.

SILVA, M. O habitus professoral: o objeto dos estudos sobre o ato de ensinar na sala de aula. Revista Brasileira de Educaçáo, Rio de Janeiro, n. 29, p.152-163, maio/jun./jul./ago. 2005. 